\title{
Oxidative Stability of Soybean Oil Enriched with Ethyl Acetate Extract of Olive By-Products
}

\author{
Semra Turan ${ }^{1, a, *}$, Deniz Günal Köroğlu ${ }^{1, b}$ \\ ${ }^{I}$ Food Engineering Department, Bolu Abant Izzet Baysal University, 14030 Bolu, Turkey \\ *Corresponding author

A R T I C L E IN F O A B S T R A C T \\ Research Article \\ In this study, oxidative stability of soybean oil (SBO) enriched with ethyl acetate extracts of olive \\ by-products was investigated. Total phenolic contents, phenolic profiles and antioxidant activities \\ of olive wastewater (OMWW) and olive pomace (OP) extracts were also determined. Total phenolic \\ contents of extracts obtained from OMWW and OP were 134.45 and $281.43 \mathrm{mg}$ gallic acid \\ Received : 14/02/2020 \\ Accepted : 13/06/2020 \\ equivalent (GAE)/g extract, respectively. While antioxidant activities of OMWW extracts in the \\ linoleic acid emulsion were in the range of $85.79 \%$ and $88.54 \%$, OP extracts had $83.30 \%$ and 90.09 \\ $\%$ at different concentrations $(0.5,1,2$ and $3 \mathrm{mg} / \mathrm{mL})$ after incubation at $37^{\circ} \mathrm{C}$. $\beta$-carotene bleaching \\ activities of the extracts at $50^{\circ} \mathrm{C}$ were found as 26.80-66.63\% in OMWW extracts and 18.76-53.32\% \\ in OP extracts, respectively. 2,2'-diphenyl-1-picrylhydrazyl (DPPH) radical scavenging activities \\ of OP extracts were higher than those of OMWW extracts and ranged from $30.6 \%$ to $87.7 \%$ in OP \\ Keywords: \\ Olive mill waste water \\ extracts and $16.6 \%$ to $54.1 \%$ in OMWW extracts at these concentrations. Both the antioxidant and \\ Olive pomace \\ Ethyl acetate extracts \\ Antioxidant activity \\ antiradical activities of extracts significantly increased with increased concentration. $\mathrm{K}_{232}$ values of \\ SBO containing ethyl acetate extracts were lower than control during the oxidation test at $60^{\circ} \mathrm{C}$. $\mathrm{OP}$ \\ extracts were more effective than OMWW extracts at $1 \mathrm{mg} / \mathrm{g}$. Results showed that ethyl acetate \\ Soybean oil \\ extracts of olive wastes could be a source of antioxidants for the stabilization of SBO.
}

\section{Introduction}

Pressing, centrifugation and sinolea methods are the main olive oil production methods. Two by-products named olive mill wastewater (OMWW) and olive pomace (OP) are obtained along with olive oil. Both of them are rich in phenolic compounds, organic acids, sugars, nitrogenous compounds, pectins and oil (Lafka et al., 2011; Chowdhury et al., 2014; Goula and Lazarides, 2015).

Olive mill by-products are the perfect sources of natural antioxidants since OMWW and OP have a considerable amount of phenolic compounds. $98 \%$ of the phenolic compounds found in olives remain in these by-products (Alu'datt et al., 2010; Lafka et al., 2011; De Marco et al., 2007; Mulinacci et al., 2001; Sánchez de Medina et al., 2011). Their high chemical oxygen demand (COD) and biochemical oxygen demand (BOD) because of their phenolic content makes them hazardous by-products to nature (Chatzistathis and Koutsos, 2017). There are some researches to minimize their hazardous effects (Mulinacci et al., 2001; Alu'datt et al., 2010; Lafka et al., 2011; Goula and Lazarides, 2015; Chowdhury et al., 2014; Paini et al., 2015; Agalias et al., 2007; Dermeche et al., 2013). And antioxidant capacities of these by-products are investigated (Farag et al., 2007; Dejong and Lanari, 2009; Cioffi et al., 2010; Orozco-Solano et al., 2011; Di Mauro et al., 2017).

Generally, synthetic antioxidants are used for increasing the oxidative stability of oils. Due to health concerns, consumers have recently preferred natural antioxidants instead of synthetic antioxidants (Balasundram et al., 2006).

This study aims to investigate the effects of OMWW and OP extracts on the oxidative stability of soybean oil (SBO) and determine their antioxidant and antiradical activities. In this study, phenolic compounds were extracted with ethyl acetate from OMWW and OP. Total phenolic contents, phenolic profiles, antioxidant and antiradical activities of extracts were determined. Schaal oven test was applied at $60^{\circ} \mathrm{C}$ to evaluate the effects of extracts on the oxidative stability of soybean oil. 


\section{Material and Methods}

\section{Materials}

OMWW and OP were obtained from an olive oil plant (Laleli Taylieli Olive and Olive Oil Plant, Burhaniye, Balikesir), which was produced by a two-phase centrifuge system. OMWW and OP were stored at $-18^{\circ} \mathrm{C}$ until their extracts were prepared.

Linoleic acid (99\%), $\beta$-carotene (99\%), butylated hydroxytoluene (BHT), hydroxytyrosol, tyrosol and oleuropein were taken from Sigma-Aldrich (St Louis, USA). 2,2'-dipyridyl (99\%) and iron (III) chloride hexahydrate were obtained from Acros Organics (New Jersey, USA). Other reagents were obtained from Merck (Darmstadt, Germany).

Determination of Some Properties of $O M W W$ and $O P$

$\mathrm{pH}$, oxidation/reduction potential, electrical conductivity and/or dissolved oxygen concentration of OMWW and OP were determined by Thermo Orion Star multi parameter (Thermo Scientific, USA). The dry matter contents of OMWW and OP were determined according to AOAC Official Method of 925.10 (AOAC, 1990). The oil contents of olive by-products were determined according to Troncosco et al. (2009).

\section{Preparation of Extracts}

$5 \mathrm{~g}$ of OMWW and $15 \mathrm{~g}$ of OP were weighted in a flask. $150 \mathrm{~mL}$ methanol was added. Then, flasks were shaken at $100 \mathrm{rpm}$ using a shaking water bath for $4 \mathrm{~h}$. After waiting overnight at $20 \pm 2^{\circ} \mathrm{C}$, all samples were filtered through a filter paper. Methanol in flasks was evaporated by a rotary evaporator. $100 \mathrm{~mL}$ acetone: water $(\% 50 \mathrm{v} / \mathrm{v})$ was added to the residue in the flasks. All flasks were washed with 50 $\mathrm{mL}$ hexane, $50 \mathrm{~mL}$ chloroform and ethyl acetate, respectively and each step was repeated 3 times. The ethyl acetate phase was collected. Then, ethyl acetate was removed under vacuum at $50^{\circ} \mathrm{C}$ using a rotary evaporator. Extracts were transferred into a colored bottle and nitrogen gas was given for $20 \mathrm{~min}$ to remove the ethyl acetate. The extraction yields were calculated as g/100 g (Chiou et al., 2007).

OMWW and OP extract solutions were prepared at 0.5 , 1,2 and $3 \mathrm{mg} / \mathrm{mL}$ concentrations. Extract solutions were used to determine DPPH antiradical and antioxidant activities using conjugated diene method in the linoleic acid system and $\beta$-carotene bleaching (BCB) test.

\section{Preparation of SBO Samples}

Ethyl acetate extracts of OMWW and OP were added into $\mathrm{SBO}$ at $1 \mathrm{mg} / \mathrm{g}$ concentration after dissolving in propanediol. Oil samples were called as SBO+OMWW and $\mathrm{SBO}+\mathrm{OP}$, respectively. SO+BHT were prepared with BHT at $0.2 \mathrm{mg} / \mathrm{g}$ concentration. All samples were vortexed thoroughly and were kept at $40^{\circ} \mathrm{C}$ for 5 minutes in an ultrasonic water bath to increase the amount of dissolved extract. SBO samples were used for the accelerated oxidation test at $60^{\circ} \mathrm{C}$.

\section{Total Phenolic Content (TPC)}

TPC of OMWW, OP, and their extracts were determined by the Folin-Ciocalteu method according to Iqbal et al. (2008). $0.002 \mathrm{~g}$ of extracts was weighted and dissolved in $1 \mathrm{~mL}$ ethyl acetate. The analysis was done by taking $0.2 \mathrm{~mL}$ of this solution. Total phenolic content was determined as mg gallic acid equivalent (GAE) per gram of extracts. The analyses were done in triplicate.

\section{Phenolic Profile of Extracts}

Tyrosol, hydroxytyrosol and oleuropein contents of the ethyl acetate extracts of OMWW and OP were determined according to Cioffi et al. (2010) with some modification. Shimadzu Prominence UFLC (Shimadzu, Japan) was used equipped with DAD detector and COL-Analytical C18 column $(5 \mu \mathrm{m}, 250 \times 4.6 \mathrm{~mm}$, Perkin Elmer, USA). The mobile phase consisted of acidified water $(0.1 \%)$ (solvent A) and methanol (solvent B). The flow rate of the mobile phase was $0.8 \mathrm{~mL} / \mathrm{min}$. The wavelength was set at $278 \mathrm{~nm}$. The gradient used during analysis was as follows: $0 \mathrm{~min}$, $100 \% \mathrm{~A} ; 2 \mathrm{~min}, 95 \% \mathrm{~A} ; 8$ min $75 \% \mathrm{~A} ; 10 \mathrm{~min}, 60 \% \mathrm{~A} ; 10$ $30 \mathrm{~min} 100 \% \mathrm{~B}, 30-35 \mathrm{~min} 40 \% \mathrm{~B}$; and $35-45 \mathrm{~min} 5 \% \mathrm{~B}$. Pure standards of tyrosol, hydroxytyrosol and oleuropein (Sigma-Aldrich, USA) at different concentrations were used.

\section{Antioxidant Activity of Extracts}

DPPH Radical Scavenging Activity of Extracts

$0.1 \mathrm{~mL}$ of OMWW or OP extract solution was mixed with $4 \mathrm{~mL}$ of DPPH reactive solution. Absorbance was measured against methanol at $517 \mathrm{~nm}$ after waiting 20 minutes in the dark using a UV-visible spectrophotometer. The same procedure was carried out in the control experiment but, $0.1 \mathrm{~mL}$ of ethyl acetate was used instead of the extract solution. Analyses were done in triplicate. Radical scavenging activity (RSA) was calculated according to the following formula as percentage inhibition (Kulisic et al., 2004; Nor et al., 2008).

$$
\operatorname{RSA}(\%)=\left(\left(\mathrm{A}_{\text {control- }}-\mathrm{A}_{\text {sample }}\right) / \mathrm{A}_{\text {control }}\right) \times 100
$$

$\mathrm{A}_{\text {control: }}$ : Absorbance of control at $t=0 \mathrm{~min}$

$A_{\text {sample: }}$ Absorbance of OMW or OP extracts at $t=20 \mathrm{~min}$

Antioxidant Activity (AA) in Linoleic Acid Emulsion by Conjugated Diene Method

Conjugated diene method in the linoleic acid emulsion was performed according to Iqbal et al. (2008) and Mau et al. (2004). $0.5 \mathrm{~mL}$ of extract solutions at different concentrations $(0.5,1,2$ ve $3 \mathrm{mg} / \mathrm{mL})$ were added to linoleic acid emulsion and incubated at $37^{\circ} \mathrm{C}$. The antioxidant activities of the extracts were calculated according to the change in absorbance values before and after oxidation. Analyses were done in triplicate.

$\mathrm{AA}(\%)=\left(\left(\Delta \mathrm{A}_{\text {control }}-\Delta \mathrm{A}_{\text {sample }}\right) / \Delta \mathrm{A}_{\text {control }}\right) \times 100$

$\Delta \mathrm{A}_{\text {control }}$ : Change in absorbance of control before and after incubation

$\Delta \mathrm{A}_{\text {sample: }}$ Change in absorbance of the sample before and after incubation 


\section{Antioxidant Activity by $\beta$-carotene Bleaching $(B C B)$ Method}

The antioxidant activity of OMWW and OP solution was determined according to $\beta$-carotene bleaching (BCB) method described by Günal and Turan (2018). About 0.3 mL of OMWW and OP extracts at different concentrations $(0.5,1,2$, and $3 \mathrm{mg} / \mathrm{mL})$ were added to linoleic acid emulsion containing $\beta$-carotene and tween 80 and allowed to stand at $50^{\circ} \mathrm{C}$ in a shaking water bath. Absorbance of emulsions was determined with 15 minutes intervals for 150 minutes. BCB activity (\%) was calculated according to the following formula using the absorbance values of the sample and control. Analyses were done in duplicate.

$$
\begin{aligned}
& \text { AA } \left.(\%)=\left(\left(\mathrm{R}_{\text {control }}-\mathrm{R}_{\text {sample }}\right) / \mathrm{R}_{\text {control }}\right)\right) \times 100 \\
& \mathrm{R}=\ln (\mathrm{a} / \mathrm{b}) / \mathrm{t} \\
& \mathrm{R} \quad=\beta \text {-carotene bleaching ratio; } \\
& \mathrm{a} \quad=\text { Absorbance at } \mathrm{t}=0 \text { min } \\
& \mathrm{b} \quad=\text { Absorbance at } \mathrm{t}=150 \text { min }
\end{aligned}
$$

\section{Accelerated Oxidation Test at $60^{\circ} \mathrm{C}$}

SBO samples were allowed to oxidize at $60^{\circ} \mathrm{C}$ for 21 days according to the Schaal oven test (Günal and Turan, 2018). $K_{232}$ and $K_{270}$ values of the oil samples taken at the beginning of the oxidation and 3 days intervals $(3,6,9,12$, $15,18,21$ days) were determined according to IUPAC methods (Paquot and Hautfenne, 1987).

\section{Statical Analyses}

The statistical analyses were performed with the SPSS package software, version 18.0 (SPSS Inc., Chicago, IL). Results were presented as means \pm standard deviation of the two or three replicates of each experiment. Analysis of variance was performed. Significant differences among the means $(\mathrm{P}<0.05)$ were determined by Duncan's multiple tests.

\section{Results and Discussion}

\section{Characterization of $O M W W$ and $O P$}

Table 1 shows some properties of OMWW, OP and their extracts. $\mathrm{pH}$ and $\mathrm{O} / \mathrm{R}$ potential, electrical conductivity, dissolved oxygen content, total dry matter content, oil content and total phenolic content of OMWW were determined as $4.97,114.5 \mathrm{mV}, 5.83 \mathrm{mS} / \mathrm{cm}, 5.95$ $\mathrm{mg} / \mathrm{L}, 5.3 \%$ (w/w), $0.10 \%$ and $0.83 \mathrm{~g} / \mathrm{kg}$, respectively. ElAbbassi et al. (2012) have specified that OMWW from two different olive oil plant had 5.2 and $5.1 \mathrm{pH}, 43$ and 13 $\mathrm{mS} / \mathrm{cm}$ electrical conductivity, 31 and $14 \mathrm{~g} / \mathrm{L}$ total organic compounds, 113 and $51 \mathrm{O}_{2} / \mathrm{L}$ chemical oxygen demand, 87 ve $48 \mathrm{~g} / \mathrm{L}$ total suspended solids, 9.82 and $6.11 \mathrm{~g} / \mathrm{L}$ total phenolic content as tyrosol equivalents. In another study, Goula and Lazarides (2015) found that OMWW from a three-phase olive mill consisted of $15.8 \%$ total solids and $7 \%$ oils. Similar results were found that OMWW from the traditional discontinuous system had $5.4 \mathrm{pH}$ and $70 \mathrm{~g} / \mathrm{L}$ total solids and total phenolic content of OMWW were 12 g GAE/L (Daâssi et al., 2014).

$\mathrm{pH}, \mathrm{O} / \mathrm{R}$ potential, total dry matter content, oil content and total phenolic content of OP pomace were found as 4.93, $117.2 \mathrm{mV}, 34.4 \%$ (w/w), 4.6\%, $1.65 \mathrm{~g} / \mathrm{kg}$, respectively. Uribe et al. (2014) found higher TPC for the fresh OP (4226.23 mg GAE/100 g d.m.) than our values.

\section{Extraction Yields and Total Phenolic Content (TPC) of Extracts}

Extraction yields of OMWW and OP extracts were determined as $1.90 \%$ and $2.53 \%$, respectively (Table 1). Lafka et al. (2001) stated that ethyl acetate extract of olive by-products from the two-phase system had the lowest extraction yield among many solvents (methanol, ethanol, isopropanol) with $33.3 \%$. Also, the extraction yield of OMWW extract was determined as $0.05 \%$ of OMWW by De Leonardis et al. (2007). Lesage-Meessen et al. (2001) emphasized that ethyl acetate extracted $9.6 \%$ and $14.2 \%$ dry residue from OMWW obtained using the two-phase and three-phase system, respectively.

It was reported that ethyl acetate was selective for low or medium molecular weight phenolic compounds (De Marco et al., 2007; Lafka et al., 2011; Visioli et al., 1999) and could not solve high molecular weight phenols especially soluble in water (Visioli et al., 1999). In a similar study, ethyl acetate was reported to be more effective in extracting phenols than $n$-propanol, chloroform and hexane (Pérez et al., 1992). It has clarified that ethyl acetate extracted a large number of monomeric phenols such as hydroxytyrosol in OMWW (El-Abbassi et al., 2012; Fki et al., 2005; Khoufi et al., 2008).

TPC of OMWW and OP extracts were determined as 134.45 and $281.43 \mathrm{mg} \mathrm{GAE} / \mathrm{g}$ extract, respectively. Daâssi et al. (2014) have specified that TPC in OMWW and its ethyl acetate extract were $12 \mathrm{~g} / \mathrm{L}$ and $28 \mu \mathrm{g} \mathrm{GAE} / \mathrm{mg}$, respectively. It was stated that TPC of ethyl acetate extract of olive mill waste was $0.43 \%$ (w/w) caffeic acid equivalent by Lafka et al. (2011). El-Abbassi et al. (2012) also stated that TPC of OMWW was 9.82 and $6.11 \mathrm{~g}$ tyrosol equivalent/L for the semi-modern and modern three-phase system, respectively. TPC of these extracts consisted mostly of flavonoids $(66.8 \%$ and $44.3 \%)$. Suárez et al. (2009) showed that OMWW extracts contained mainly phenolic alcohol, phenolic acids, and secoiridoid derivatives

Table 1. Characterization of OMWW and OP, extraction yield and total phenolic content of their extracts

\begin{tabular}{l|cc}
\hline & OMWW & OP \\
\hline $\mathrm{pH}$ & $4.97 \pm 0.01$ & $4.93 \pm 0.02$ \\
O/R potential (mV) & $114.5 \pm 0.1$ & $117.2 \pm 0.1$ \\
Conductivity (mS/cm) & $5.83 \pm 0.00$ & - \\
Dissolved oxygen (mg/L) & $5.95 \pm 0.01$ & - \\
Total dry matter (\%) & $5.3 \pm 0.0$ & $34.4 \pm 34.4$ \\
Oil content (\%) & $0.10 \pm 0.03$ & $4.6 \pm 0.24$ \\
Total Phenolic Content (g/kg) & $0.83 \pm 0.10$ & $1.65 \pm 0.03$ \\
Extraction Yield (\%) & $1.90 \pm 0.01$ & $2.58 \pm 0.08$ \\
Total Phenolic Content of Extracts (mg GAE/g extract) & $134.45 \pm 8.6$ & $281.43 \pm 24.2$ \\
\hline
\end{tabular}




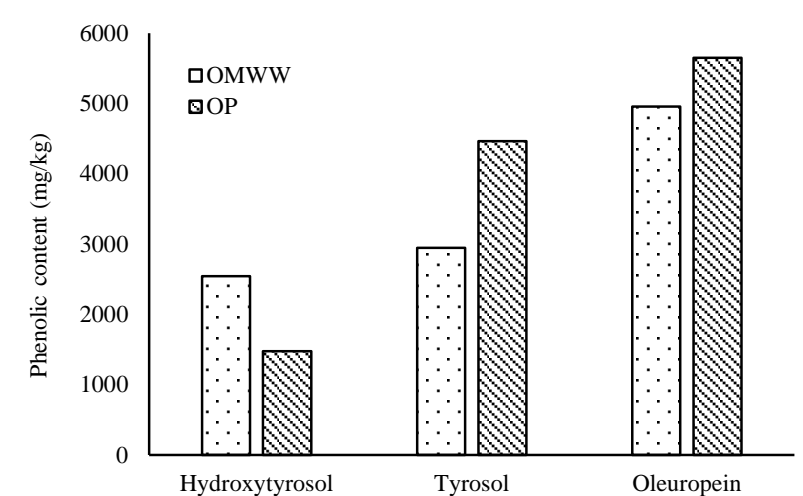

Figure1. Phenolic profile of OMWW and OP ethyl acetate extracts $(\mathrm{mg} / \mathrm{kg})$

Olive mill wastewater, OMWW; OP, Olive pomace

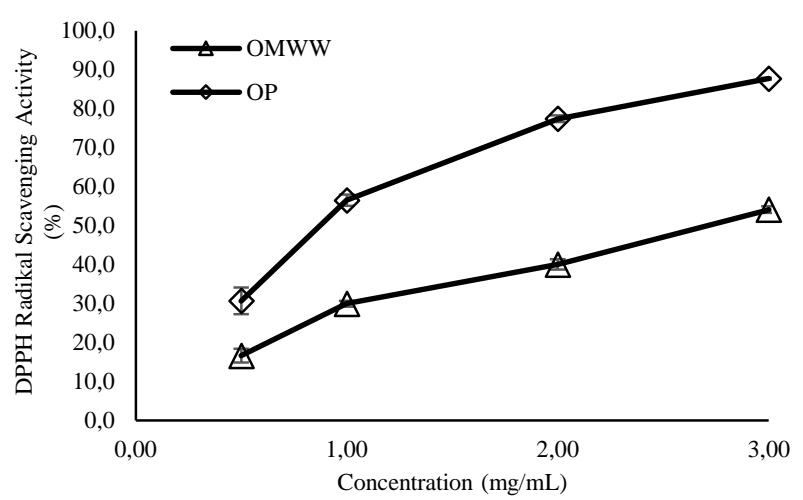

Figure 2. DPPH radical scavenging activities (\%) of OMWW and OP ethyl acetate extracts

Olive mill wastewater, OMWW; OP, Olive pomace

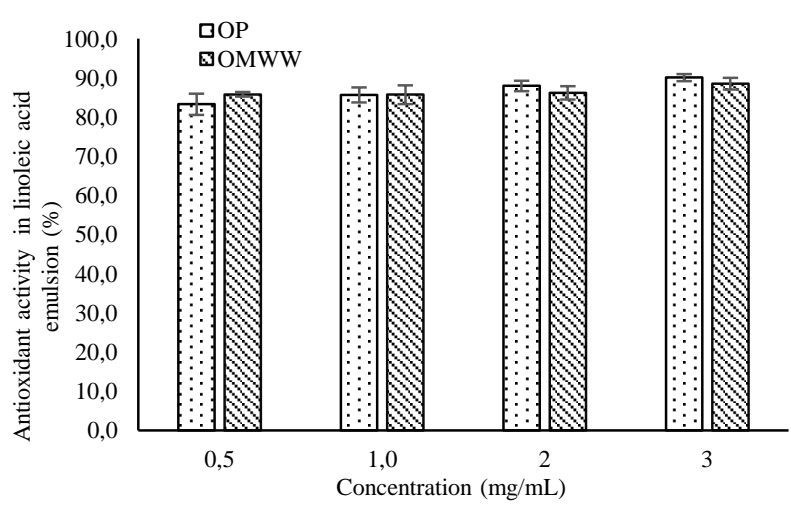

Figure 3. Antioxidant of activities (\%) of OMWW and OP ethyl acetate extracts in linoleic acid emulsion Olive mill wastewater, OMWW; OP, Olive pomace

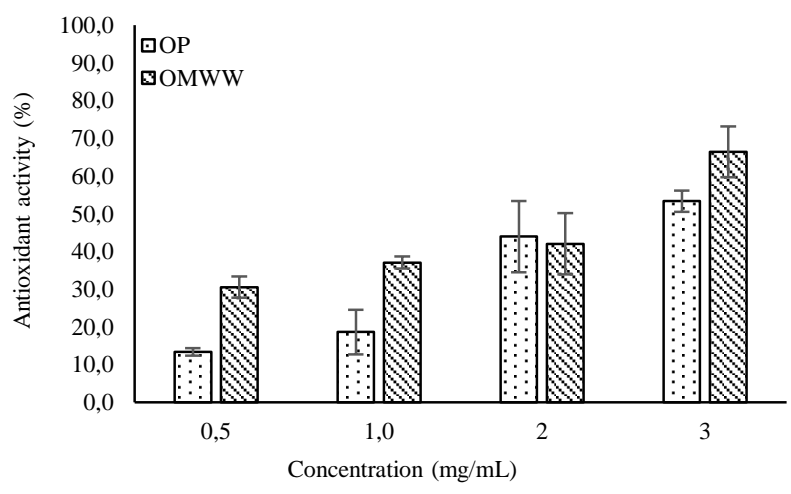

Figure 4. Antioxidant activities (\%) of OMWW and OP ethyl acetate extracts by $\beta$-carotene bleaching method Olive mill wastewater, OMWW; OP, Olive pomace

\section{Phenolic profile of $\mathrm{OMWW}$ and $\mathrm{OP}$ extracts}

Hydroxytyrosol, tyrosol and oleuropein of the OMWW and OP extracts are shown in Figure 1. Ethyl acetate extracts of OMWW and OP had 2543.2 and $1478.6 \mathrm{mg} / \mathrm{kg}$ hydroxytyrosol; 2949.7 and $4462.4 \mathrm{mg} / \mathrm{kg}$ tyrosol; and 4957.4 and $5648.4 \mathrm{mg} / \mathrm{kg}$ oleuropein, respectively.

Dejong and Lanari (2009) have remarked that wastewater extract of OP from the two phase system contained $70.6 \%$ hydroxytyrosol, $17.5 \%$ tyrosol, $9.5 \%$ caffeic acid, $1.9 \%$ p-coumaric acid, and $0.3 \%$ vanillic acid. De Leonardis et al. (2007) have investigated that OMWW consists of $66.7 \%$ hydroxytyrosol, $16.7 \%$ tyrosol, $8.3 \%$ caffeic acid, \%8.3 ferulic acid. Additionally, it has been reported that pomace methanol extracts consisted of oleuropein, lingstroside aglycone, oleuropein aglycone, gallic acid, hydroxytyrosol, tyrosol, caffeic acid (Cioffi et al., 2010).

\section{DPPH Radical Scavenging Activity}

Free radical scavenging is one of the known mechanisms by which antioxidants inhibit lipid oxidation. The method of scavenging DPPH free radicals can be used to evaluate the antioxidant activity of specific compounds or extracts in a short time (Cheung et al., 2003). DPPH radical scavenging activity $(\%)$ of extracts are given in Figure 2.

OP extracts had higher DPPH radical scavenging activity than OMWW extracts. Radical scavenging activities of extracts significantly increased with the increased concentration $(\mathrm{P}<0.05)$. Radical scavenging activities ranged from $30.6 \%$ to $87.7 \%$ in OP extracts and from $16.6 \%$ to $54.1 \%$ in OMWW extracts. In a similar study, BHA, BHT and $\alpha$-tocopherol at $0.2 \mathrm{mg} / \mathrm{mL}$ had $49.96 \%, 12.81 \%$, and $33.20 \%$ radical scavenging activity, respectively (Günal and Turan, 2018). OP extracts had higher values at $1-3 \mathrm{mg} / \mathrm{mL}$ concentrations compared to these values and OMWW extracts at 2 and $3 \mathrm{mg} / \mathrm{mL}$ concentrations had higher values than BHT and $\alpha$ tocopherol. Additionally, radical scavenging activities of methanol and ethanol extracts of OMWW and OP reported in the range of $14.67 \%-63.52 \%$ and $10.64 \%-54.85 \%$, respectively (Günal and Turan, 2018). Compared to the methanol and ethanol extracts, ethyl acetate extract of OP had higher values, although OMWW had similar values.

Lafka et al. (2011) reported that ethyl acetate extract of olive by-products had $34.2 \%$ inhibition. In the same study, ethyl acetate extract had the lowest inhibition compared to methanol, ethanol, n-propanol and isopropanol extracts. Ethyl acetate extraction was not effective in the extraction of phenols among polar solvents having good water solubility (Moure et al., 2001).

\section{Antioxidant Activity in Linoleic Acid Emulsion}

During incubation of linoleic acid emulsion at $37^{\circ} \mathrm{C}$, linoleic acid was oxidized by means of heat and oxygen. Antioxidants present in extract solutions inhibit linoleic acid oxidation to a certain extent.

Antioxidant activities of extracts in linoleic acid emulsion is shown in Figure 3. As the concentration increased, there was a slight increase in the antioxidant activities of the extracts in the linoleic acid emulsion. This increase was significant $(\mathrm{P}<0.05)$ for OP extract. However, the change in the antioxidant activities of OMWW extract 
in linoleic acid emulsion was found insignificant $(\mathrm{P}>0.05)$. Besides, the obtained values were close to each other for the same concentrations of OMWW and OP extracts. While antioxidant activities of OMWW in the linoleic acid emulsion were in the range of $85.79 \%$ and $88.54 \%$, antioxidant activities of OP were $83.30 \%$ and $90.09 \%$. Aissa et al. (2017) clarified that ethyl acetate extract of OMWW had $256.57 \mu \mathrm{g} / \mathrm{mL} \mathrm{IC}_{50}$ value in linoleic acid emulsion.

\section{Antioxidant Activity by BCB Method}

Yellow color of the $\beta$-carotene diminishes because of the active radicals generated during linoleic acid oxidation in this method. Antioxidants in extracts slowed down the bleaching rate of $\beta$-carotene (Kulisic et al., 2004).

Antioxidant activities (\%) of the extracts determined by BCB method increased with increasing concentration $(\mathrm{P}<0.05)$ (Figure 4). The highest decline in absorbance was observed in the control sample during the incubation period of 150 minutes. The absorbances of samples containing OMWW and OP extracts decreased more slowly than the control sample. This means that phenolic compounds in samples inhibit radical formation via oxidation of linoleic acid, thus the bleaching of $\beta$-carotene. According to the BCB method, antioxidant activities of OMWW and OP extracts were in the range of $26.89-66.63 \%$ and 18.76 $53.32 \%$ at the studied concentrations $(0.5-3 \mathrm{mg} / \mathrm{mL})$, respectively. Contrary to total phenolic contents of the extracts, OMWW extracts had higher antioxidant activities than OP extracts according to BCB method. In our another study, the antioxidant activities of BHA, BHT and $\alpha-$ tocopherol at $0.2 \mathrm{mg} / \mathrm{mL}$ concentration in $\mathrm{BCB}$ method were found as $95.85 \%, 95.23 \%$ and $92.81 \%$, respectively (Günal and Turan, 2018). Ethyl acetate extracts had lower antioxidant activities than these antioxidants. In addition, the antioxidant activities of methanol and ethanol extracts of OMWW and OP ranged from $32.19 \%$ to $84.06 \%$ in our previous study (Günal and Turan, 2018). These values were higher than the values of OMWW and OP ethyl acetate extracts in this study.

\section{Accelerated Oxidation Test}

The change in $\mathrm{K}_{232}$ and $\mathrm{K}_{270}$ values during the oxidation of SBO samples at $60^{\circ} \mathrm{C}$ is shown in Table 2. Primary oxidation products (hydroperoxides, conjugated dienes) and secondary oxidation products (aldehydes, ketones, short-chain fatty acids, alcohols, conjugated trienes) cause an increase in absorbance at 232-234 nm and 268-270 nm, respectively (Suja et al., 2004). Therefore, it is possible to obtain information about oil oxidation by measuring the absorbance values at these wavelengths.

As the primary oxidation products increased gradually over time under accelerated oxidation conditions, $\mathrm{K}_{232}$ values of all samples increased significantly $(\mathrm{P}<0.05) . \mathrm{K}_{232}$ value of SBO increased from 6.06 to 20.53 until the end of the $21^{\text {st }}$ day. Addition of extracts to SBO increased slightly the resistance of the oil to oxidation. $\mathrm{K}_{232}$ values of SBO+OMWW and SBO+OP increased to 17.41 and 17.52 at the end of the $21^{\text {st }}$ day, respectively. These values were lower than SBO and SBO+BHT. The change in $\mathrm{K}_{232}$ values of oil groups was found insignificant $(\mathrm{P}>0.05)$ between $3^{\text {rd }}$ $-15^{\text {th }}$ days. At $18^{\text {th }}$ and $21^{\text {st }}$ days of the oxidation, significant changes $(\mathrm{P}<0.05)$ were observed in $\mathrm{K}_{232}$ values of oil groups.

When $\mathrm{K}_{270}$ values were taken into consideration, there were fluctuations in these values during oxidation of all samples. The change in $\mathrm{K}_{270}$ values of oil samples taken at different days was found significant $(\mathrm{P}<0.05)$ except for in those of SBO +OMWW samples. The $\mathrm{K}_{270}$ value of SBO increased slightly from 1.93 to 2.65 after 21 days. SBO had slightly higher $\mathrm{K}_{270}$ value than those of SBO+OMWW, $\mathrm{SBO}+\mathrm{OP}$ and $\mathrm{SBO}+\mathrm{BHT}$. However, $\mathrm{K}_{270}$ values of oil groups ware found insignificant $(\mathrm{P}>0.05)$ for all storage days.

Table 2. $\mathrm{K}_{232}$ and $\mathrm{K}_{270}$ values of SBO samples at $60^{\circ} \mathrm{C}$

\begin{tabular}{|c|c|c|c|c|}
\hline Days & SBO & SBO+OMWW & $\mathrm{SBO}+\mathrm{OP}$ & $\mathrm{SBO}+\mathrm{BHT}$ \\
\hline \multicolumn{5}{|c|}{$\mathrm{K}_{232}$} \\
\hline 0 & $6.06 \pm 0.03^{\mathrm{eB}}$ & $6.00 \pm 0.03^{\mathrm{eB}}$ & $5.95 \pm 0.24^{\mathrm{hB}}$ & $6.78 \pm 0.05^{\mathrm{dA}}$ \\
\hline 3 & $7.48 \pm 0.01^{\mathrm{eA}}$ & $7.57 \pm 0.26^{\mathrm{deA}}$ & $7.74 \pm 0.06^{\mathrm{gA}}$ & $9.29 \pm 1.70^{\mathrm{cA}}$ \\
\hline 6 & $9.30 \pm 0.26^{\mathrm{dA}}$ & $9.07 \pm 1.00^{\mathrm{cdA}}$ & $8.72 \pm 0.05^{\mathrm{fA}}$ & $10.06 \pm 0.24^{\mathrm{cA}}$ \\
\hline 9 & $10.52 \pm 0.03^{\mathrm{dA}}$ & $10.10 \pm 0.09^{\mathrm{cA}}$ & $9.85 \pm 0.65^{\mathrm{eA}}$ & $10.68 \pm 0.74^{\mathrm{cA}}$ \\
\hline 12 & $13.62 \pm 0.62^{\mathrm{cA}}$ & $13.99 \pm 1.79^{\mathrm{bA}}$ & $12.63 \pm 0.18^{\mathrm{dA}}$ & $13.90 \pm 0.06^{\mathrm{bA}}$ \\
\hline 15 & $15.34 \pm 1.51^{\mathrm{cA}}$ & $14.86 \pm 0.29^{\mathrm{bA}}$ & $13.77 \pm 0.24^{\mathrm{cA}}$ & $15.93 \pm 2.02^{\mathrm{bA}}$ \\
\hline 18 & $17.73 \pm 0.87^{\mathrm{bAB}}$ & $16.76 \pm 0.86^{\mathrm{aAB}}$ & $16.39 \pm 0.29^{\mathrm{bB}}$ & $18.66 \pm 0.51^{\mathrm{aA}}$ \\
\hline 21 & $20.53 \pm 1.04^{\mathrm{aA}}$ & $17.41 \pm 0.48^{\mathrm{aB}}$ & $17.52 \pm 0.17^{\mathrm{aB}}$ & $19.16 \pm 0.50^{\mathrm{aAB}}$ \\
\hline \multicolumn{5}{|c|}{$\mathrm{K}_{270}$} \\
\hline 0 & $1.93 \pm 0.02^{\mathrm{bA}}$ & $1.92 \pm 0.00^{\mathrm{bA}}$ & $1.91 \pm 0.08^{\mathrm{cA}}$ & $1.90 \pm 0.02^{\mathrm{cA}}$ \\
\hline 3 & $1.95 \pm 0.08^{\mathrm{bA}}$ & $1.98 \pm 0.05^{\mathrm{bA}}$ & $2.04 \pm 0.03^{\mathrm{cA}}$ & $2.09 \pm 0.24^{\mathrm{bcA}}$ \\
\hline 6 & $1.96 \pm 0.06^{\mathrm{bA}}$ & $1.93 \pm 0.20^{\mathrm{bA}}$ & $1.89 \pm 0.02^{\mathrm{cA}}$ & $2.00 \pm 0.04^{\mathrm{bcA}}$ \\
\hline 9 & $1.92 \pm 0.01^{\mathrm{bA}}$ & $1.97 \pm 0.05^{\mathrm{bA}}$ & $1.90 \pm 0.14^{\mathrm{cA}}$ & $1.88 \pm 0.09^{\mathrm{cA}}$ \\
\hline 12 & $2.29 \pm 0.21^{\mathrm{abA}}$ & $2.49 \pm 0.37^{\mathrm{abA}}$ & $2.28 \pm 0.11^{\mathrm{bA}}$ & $2.25 \pm 0.04^{\mathrm{abcA}}$ \\
\hline 15 & $2.31 \pm 0.11^{\mathrm{abA}}$ & $2.31 \pm 0.08^{\mathrm{abA}}$ & $2.26 \pm 0.16^{\mathrm{bA}}$ & $2.47 \pm 0.39^{\mathrm{abA}}$ \\
\hline 18 & $2.63 \pm 0.44^{\mathrm{aA}}$ & $2.68 \pm 0.48^{\mathrm{aA}}$ & $2.53 \pm 0.03^{\mathrm{aA}}$ & $2.71 \pm 0.34^{\mathrm{aA}}$ \\
\hline 21 & $2.65 \pm 0.26^{\mathrm{aA}}$ & $2.38 \pm 0.01^{\mathrm{abA}}$ & $2.34 \pm 0.02^{\mathrm{abA}}$ & $2.39 \pm 0.13^{\mathrm{abcA}}$ \\
\hline
\end{tabular}

Analyses were done in duplicate. SBO, soybean oil; OMWW, olive mill wastewater at $1 \mathrm{mg} / \mathrm{g}$ concentration; OP, olive pomace at $1 \mathrm{mg} / \mathrm{g}$ concentration, BHT, butylated hydroxytoluene at $0.2 \mathrm{mg} / \mathrm{g},{ }^{\mathrm{a}-\mathrm{g}}$ Shows the difference between days in the same oil $(\mathrm{P}<0.05)$, ${ }^{\mathrm{A}-\mathrm{B}}$ Shows the difference between oils in the same day $(\mathrm{P}<0.05)$ 
Under accelerated oxidation conditions, PO and OMWW extracts were more effective than BHT. The extracts were found to be more effective in inhibiting the formation of primary and secondary oxidation products compared to $\mathrm{SBO}+\mathrm{BHT}$.

\section{Conclusion}

When the total phenolic content and antioxidant activities were taken into consideration, ethyl acetate extracts of OMWW and OP were considered as a highly effective antioxidant source. Furthermore, when the accelerated oxidation test was evaluated, it was seen that OMWW and OP extracts were more effective than BHT, which is a synthetic antioxidant. Ethyl acetate can be selected for extraction phenolic compounds from olive byproducts due to high antioxidant activities. In later studies, the dominant phenolic compounds contained in these extracts can be purified and the effects of these phenolic compounds on oxidation can be examined. Besides, the effects of these extracts at different temperatures can be examined by applying thermal oxidation tests or frying at higher temperatures.

\section{Acknowledgement}

Authors would like to thank Bolu Abant Izzet Baysal University Scientific Research Projects for funding this research (Project No: 2012.09.01.505) and Bolu Abant Izzet Baysal University YENIGIDAM for the analyses of phenolic profile of extracts.

\section{References}

Agalias A, Magiatis P, Skaltsounis AL, Mikros E, Tsarbopoulos A, Gikas E, Manios T. 2007. A New Process for the Management of Olive Oil Mill Waste Water and Recovery of Natural Antioxidants. J Agric Food Chem, 55: 2671-2676.

Aissa I, Kharrat N, Aloui F, Sellami M, Bouaziz M, Gargouri Y. 2017. Valorization of antioxidants extracted from olive mill wastewater. Biotechnol Applied Biochem, 64(4): 579-589.

Alu'datt M, Alli I, Ereifeja K, Alhamad M, Al-Tawaha A, Rababah T. 2010. Optimisation, characterisation and quantification of phenolic compounds. Food Chem, 123: 117122.

AOAC. 1990. Method 925.10. In Official Methods of Analysis of the Association of Official Analytical Chemists, Association of Official Analytical Chemists. Washington, DC.

Araújo M, Pimentel F, Alves R, Oliveira M. 2015. Phenolic compounds from olive mill wastes: Health effects, analytical approach and application as food antioxidants. Trends Food Sci Technol, 45: 200-211.

Balasundram N, Sundram K, Samman S. 2006. Phenolic compounds in plants and agri-industrial by-products: Antioxidant activity, occurrence, and potential uses. Food Chem, 99: 191-203.

Chatzistathis T, Koutsos T. 2017. Olive mill wastewater as a source of organic matter, water and nutrients for restoration of degraded soils and for crops managed with sustainable systems. Agr Water Manage, 190: 55-64.

Chowdhury A, Michailides M, Akratos C, Tekerlekopoulou A, Pavlou S, Vayenas D. 2014. Composting of three phase olive mill solid waste using different. Int Biodeter Biodegr, 91: 6673.
Cioffi G, Pesca M, De Caprariis P, Braca A, Severino L, De Tommasi N. 2010. Phenolic compounds in olive oil and olive pomace from Cilento (Campania, Italy) and their antioxidant activity. Food Chem, 121: 105-111.

Chiou A, Salta FN, Kalogeropoulos N, Mylona A, Ntalla I, Andrikopoulos N K, 2007. Retention and distribution of polyphenols after pan-frying of French fries in oils enriched with olive leaf extract. J Food Sci, 72(8): S574-S584.

Daâssi D, Lozano-Sánchez J, Borrás-Linares I, Belbahri L, Woodward S, Zouari-Mechichi H, Mechichi T, Nasri M, Segura-Carretero A. 2014. Olive oil mill wastewaters: Phenolic content characterization during degradation by Coriolopsis gallica. Chemosphere, 113: 62-70.

De Leonardis A, Macciola V, Lembo G, Aretini A, Nag A. 2007. Studies on oxidative stabilisation of lard by natural antioxidants recovered from olive-oil mill wastewater. Food Chem, 100: 998-1004.

De Marco E, Savarese M, Paduano A, Sacchi R. 2007. Characterization and fractionation of phenolic compounds. Food Chem, 104: 858-867.

Dejong S, Lanari M. 2009. Extracts of olive polyphenols improve lipid stability in cooked beef and pork: Contribution of individual phenolics to the antioxidant activity of the extract. Food Chem, 116: 892-897.

Dermeche S, Nadoura M, Larroche C, Moulti-Mati F, Michaud P. 2013. Olive mill wastes: Biochemical characterizations and valorization. Process Biochem, 48: 1532-1552.

Di Mauro, M Giardina R, Fava G, Mirabella E, Acquaviva R, Renis M, D’Antona N. 2017. Polyphenolic profile and antioxidant activity of olive mill wastewater from two Sicilian olive cultivars: Cerasuola and Nocellara etnea. Euro Food Res Technol, 243: 1895-1903.

El-Abbassi A, Kiai H, Hafidi A. 2012. Phenolic profile and antioxidant activities of olive mill wastewater. Food Chem, 132: 406-412.

Farag R, Mahmoud E, Basuny A. 2007. Use crude olive leaf juice as a natural antioxidant for the stability sunflower oil during heating. Int J Food Sci Technol, 42: 107-115.

Fki I, Allouche N, Sayadi S. 2005. The use of polyphenolic extract, purified hydroxytyrosol and 3,4-dihydroxyphenyl acetic acid from olive mill wastewater for the stabilization of refined oils: a potential alternative to synthetic antioxidants. Food Chem, 93: 197-204.

Goula A, Lazarides H. 2015. Integrated processes can turn industrial food waste into valuable food. J Food Eng, 167: 45-50.

Günal D, Turan S. 2018. Effects of olive wastewater and pomace extracts, lecithin, and ascorbyl palmitate on the oxidative stability of refined sunflower oil. J Food Process Preserv, 42(9): e13705.

Iqbal S, Haleem S, Akhtar M, Zia-ul-Haq, M, Akbar J. 2008. Efficiency of pomegranate peel extracts in stabilization of sunflower oil under accelerated conditions. Food Res Int, 41: 194-200.

Khoufi S, Aloui F, Sayadi S. 2008. Extraction of antioxidants from olive mill wastewater and electro-coagulation of exhausted fraction to reduce its toxicity on anaerobic digestion. J Hazard Mater, 151: 531-539.

Kulisic T, Radonic A, Katalinic V, Milos M. 2004. Use of different methods for testing antioxidative activity of oregano essential oil. Food Chem, 85: 633-640.

Lafka TI, Lazou A, Sinanoglou V, Lazos E. 2011. Phenolic and antioxidant potential of olive oil mill wastes. Food Chem, 125(1): 92-98

Lesage-Meessen L, Navarro D, Maunier S, Sigoillot JC, Lorquin J, Delattre M, Simon J L, Aster M, Labat M. 2001. Simple phenolic content in olive oil residues as a function of extraction systems. Food Chem, 75: 501-507. 
Mau JL, Chang CN, Huang SJ, Chen CC. 2004. Antioxidant properties of methanolic extracts from Grifola frondosa, Morchella esculenta and Termitomyces albuminosus mycelia. Food Chem, 87: 111-118.

Moure A, Cruz J, Franco D, Manuel Domínguez J, Sineiro J, Domínguez H, Núñez MJ, Carlos Parajó, J. 2001. Natural antioxidants from residual sources. Food Chem, 72: 145-171.

Mulinacci N, Romani A, Galardi C, Pinelli P, Giaccherini C, Vincieri F. 2001. Polyphenolic Content in Olive Oil Waste Waters and Related Olive. J Agric Food Chem, 49(8): 3509-3514.

Orozco-Solano M, Priego-Capote F, Luque de Castro M. 2011. Influence of Simulated Deep Frying on the Antioxidant Fraction of Vegetable Oils after Enrichment with Extracts from Olive Oil Pomace. J Agric Food Chem, 59: 9806-9814.

Paini, M, Aliakbarian B, Casazza A, Lagazzo A, Botter R, Prego P. 2015. Microencapsulation of phenolic compounds from olive pomace using spray drying: A study of operative parameters. LWT - Food Sci Technol, 62: 177-186.

Paquot C, Hautfenne A. 1987. Standard methods for the analysis of oils, fats and derivatives. In C. Paquot, A. Hautfenne (Eds), International union of pure and applied chemistry (IUPAC). London: Blackwell Scientific Publications.

Pérez J, De La Rubia T, Moreno J, Martinez J. 1992. Phenolic content and antibacterial activity of olive oil waste waters. Environ Toxicol Chem, 11(4): 489-495.
Sánchez de Medina V, Priego-Capote F, Jiménez-Ot, C, Luque de Castro M. 2011. Quality and Stability of Edible Oils Enriched with Hydrophilic Antioxidants from the Olive Tree: The Role of Enrichment Extracts and Lipid Composition. J Agric Food Chem, 59: 11432-11441.

Suárez M, Romero MP, Ramo T, Macià A, Motilva MJ. 2009. Methods for Preparing Phenolic Extracts from Olive Cake for Potential Application as Food Antioxidants. J Agric Food Chem, 57: 1463-1472.

Suja K, Abraham J, Thamizh S, Jayalekshmy A, Arumughan C. 2004. Antioxidant efficacy of sesame cake extract in vegetable oil protection. Food Chem, 84: 393-400.

Troncoso E, Pedreschi F, Zúñigac R. 2009. Comparative study of physical and sensory properties of pre-treated potato slices during vacuum and atmospheric frying. LWT-Food Sci Technol, 42(1): 187-195.

Uribe E, Lemus-Mondaca R, Vega-Gálvez A, Zamorano M, Quispe-Fuentes I, Pasten A, Di Scala K. 2014. Influence of process temperature on drying kinetics, physicochemical properties and antioxidant capacity of the olive-waste cake. Food Chem, 147: 170-176.

Visioli F, Romani A, Mulinacci N, Zarini S, Conte D, Vincieri F, Galli C. 1999. Antioxidant and Other Biological Activities of Olive Mill Waste Waters. J Agric Food Chem, 47: 33973401 . 